\title{
Study to assess the health issues among employees working in selected call centres of Mangalore
}

\author{
Insha Maqbool ${ }^{1}$, Dr. Devina E Rodrigues ${ }^{2}$, Mr. Kiran Rao Chavan ${ }^{3}$ \\ 1M.Sc Nursing, Dept. of Community Health Nursing, Yenepoya Nursing College, Yenepoya (Deemed to be University), Deralakatte, Mangaluru, \\ Karnataka, India.
}

${ }^{2}$ Professor, Dept. of Community Health Nursing, Yenepoya Nursing College, Yenepoya (Deemed to be University), Deralakatte, Mangaluru, Karnataka, India.

${ }^{3}$ Assistant Professor, Dept. of Community Health Nursing, Yenepoya Nursing College, Yenepoya (Deemed to be University), Deralakatte, Mangaluru, Karnataka, India.

\begin{abstract}
Background: The new mantra for job opportunities among young population is "call center". Though Bangalore is considered as hub for call centres, the slowly call centres are emerging in Mangalore. Since this job has got a lot of mental pressure, it can be even exhibited in the form of physical and physiological symptoms. Hence, an attempt has been made by the investigator to assess the health issues among call centre employees. Objectives: A descriptive study aimed to assess the health issues among employees working in selected call centres. Materials and Methods: Convenience sampling technique was used to select the sample size of 80 call centre employees. The dichotomous questionnaire having 22 items and baseline proforma having 16 items were given for the subjects to place their responses. Results: The present study revealed that overall percentage of health issues was around $19 \%$ that shows the employees had one or the other type of health issue. Headache was the most frequent complaint (66.3\%) sounded by the subjects. Second common complaint was eye strain (45\%) followed by back pain (43\%). Less proportion (28.8\%) of the respondents were restless and $27.5 \%$ had gained weight. There was a significant association between age $\left(\chi^{2}=16.20, p<0.05\right)$, gender $\left(\chi^{2}=6.5, p\right.$ $<0.05)$, religion $\left(\chi^{2}=33.80, p<0.05\right)$, marital status $\left(\chi^{2}=49.37, p<0.05\right)$, type of family $\left(\chi^{2}=45.0, p<0.05\right)$, habits $\left(\chi^{2}=174.1, p<0.05\right)$, frequency of habits $\left(\chi^{2}=48.05, p<0.05\right)$, years of job experience $\left(\chi^{2}=28.67, p<0.05\right)$, type of shift $\left(\chi^{2}=45.0, p<0.05\right)$, average number of working hours $\left(\chi^{2}=72.20, p<0.05\right)$, rest period $\left(\chi^{2}=54.45, p<0.05\right)$, duration of rest period $\left(\chi^{2}=25.87, p<0.05\right)$ and participation in health awareness program $\left(\chi^{2}=76.05, p<0.05\right)$ with baseline characteristics. Conclusion: From the findings, it can be inferred that the longer the working hours, the more the health issues. The rest period ensures the less health issues. More the years of job experience more will be the health issues, the smokers had more health issues than the non smokers.
\end{abstract}

Keywords: Health issues, employees, call centres

Article Info: Received 26 Sep 2018; Review Completed 24 Oct 2018; Accepted 25 Oct 2018; Available online 15 Nov 2018

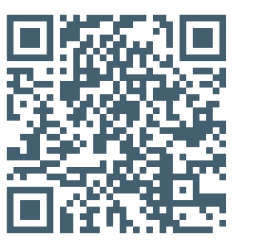

\section{Cite this article as:}

Insha M, Rodrigues DE, Chavan KR, Study to assess the health issues among employees working in selected call centres of Mangalore, Journal of Drug Delivery and Therapeutics. 2018; 8(6):58-61

DOI: http://dx.doi.org/10.22270/jddt.v8i6.2011

Ms. Insha Maqbool, M.Sc Nursing, Department of Community Health Nursing, Yenepoya Nursing College, Yenepoya (Deemed to be University), Deralakatte, Mangaluru, Karnataka, India, 575018.

\section{INTRODUCTION}

In the last two decades, India has witnessed a very rapid economic growth. One of the most important factors related to this rising growth has been the information technology (IT) industry. Business Process Outsourcing (BPOs) companies have mushroomed and are a visible concrete expression of this IT revolution. The availability of cheap labor costs and the pool of skilled, English-speaking workforce are the foremost factors for the call center boom in the country. ${ }^{1,2}$ When a company concentrates on the core business and out sources its noncore activities like payment services, customer services and administration, then it is referred to as $\mathrm{BPO} .^{3}$

The new mantra for job opportunities among young population is "call center". A call center is a voice-based part of a BPO organization. Call center is defined as any communications platform from which firms deliver services to customers via remote Real-time contact. 4

Human resources play a vital role in the successful functioning of these organizations. Their prime duty is to 
provide the customers with the needed information, so organizations recruit them with great care and spend a lot in training them also. But the news in the magazines and newspapers depict that the call centre employees are facing a lot of problems like excessive workload, unreachable targets, and pressurizing and abusive customers. Above all, continuous night shifts create biological imbalance in them and finally makes them stressful. Stress is an important problem encountered by the call centre employees. ${ }^{5}$

The Tamil daily Dinamalar (2004) states that Burn Out Stress Syndrome (BOSS) affects young people in the computer field. It occurs due to increased depression which affects the well being of the individual. BOSS generally affects those working in call centers, BPO offices and those working on continuous night shifts. As these employees have to sit continuously for eight hours, they get back pain which is the primary symptom of BOSS. The other symptoms of BOSS are tiredness due to loss of sleep and results in mental depression followed by problems in respiratory system, digestive system and ultimately affects the biological clock. So it becomes necessary to act according to the biological clock to make the body parts and organs function effectively. BOSS is a popular phenomenon mentioned by Peptone. It can be defined as the consequence of high levels of job stress, personal frustration and inadequate coping skills. ${ }^{6}$

Life Style in Call Centers affects Sleep Quality and the workers work at times when they would normally be sleeping, this could challenge the individual's circadian rhythm because the sleep-wake internal clock setting is at odds with sleep wake cycle of the shift schedule ultimately resulting in circadian rhythm sleep disorders. ${ }^{7}$ Occupational health experts of Bangalore reported that permanent night shift duties resulted in serious health concerns for call center employees, wherein sleep disorder were observed among $83 \%$ as compared with industry average (IT enabled services) of $39.5 \% .^{8}$

Call Centre employment not only demands cultural transformation, nocturnal labour and hours of monotonous work from its employees but also brings with it insecurities and vulnerabilities by diminishing their interpersonal, familial and social interactions. Many employees felt socially alienated, completely cut-off from their family and friends circuit owing to nocturnal labour. Some also complained of having little time to spend with their family members even though they were physically present at home during daytime. ${ }^{9}$

Effect on mental health mainly includes burnout stress syndrome which is seen very commonly among people working in call centers. The symptoms of this syndrome include chronic fatigue; insomnia and complete alteration of 24-hour biological rhythm of the body are routine cause for sickness absenteeism. ${ }^{10}$

The dynamics of technology and innovation has now developed talented workforce on employees of call centre Industry. Irregular sleeping, working hours, time pressure, high call volume and low job security are the main stressors found among call centre employees. Though Bangalore is considered as hub for call centres, the slowly call centres are emerging in Mangalore and many graduates are joining call centres as it fixtures descent salary and easy access to get jobs. Since this job has got a lot of mental pressure, it can be even exhibited in the form of physical and physiological symptoms. Hence, an attempt has been made by the investigator to assess the physical health issues among call centre / BPO / IT employees.

\section{MATERIALS AND METHODS}

Sample setting and sample size: The research design selected for this study was descriptive design. The study was carried out in selected call centres located at Mangalore. Convenience sampling technique was used to select the sample size of 80 call centre employees.

Tools and techniques: A baseline proforma having 16 items and dichotomous questionnaire with 22 items under 6 domains [ $\mathrm{r}=0.83$ ] to assess the health issues was administered to collect the data from the employees.

Data analysis: The data was collected after obtaining prior permission from the concerned authority to conduct the study. The participants were assured about the confidentiality of their responses. The data was analyzed in terms of objectives of the study using both descriptive and inferential statistics. The data obtained was plotted in the master sheets.

\section{RESULTS}

Majority of the subjects $(72.50 \%)$ were young adults in the age group of 21-30 years. The highest proportion of the subjects $(81.30 \%)$ were graduates and $18.80 \%$ were post graduates. The monthly income varied from Rs. 11,000 to above 30,000 and almost half proportion (48.8\%) were drawing salary above Rs. 30,000 per month. This shows that Call Centres pay a descent salary for their employees. Majority of the respondents (88.8\%) had no habits, $7.5 \%$ were having the habit of smoking, $2.50 \%$ were taking alcohol and only $1.30 \%$ was chewing gutkha. Highest proportion of the subjects (87\%) had morning shifts. Almost all the subjects $(97.5 \%)$ were working $9-12$ hours per day and only $2.6 \%$ were working less than 8 hours a day. Maximum proportion of the respondents (91\%) was permitted to take rest in between the working hours and only $9 \%$ were not permitted for taking rest. Less than half of the subjects $(38.8 \%)$ had more than 1 hour duration of rest period. More than two-third proportion (78.8\%) were not undergone annual health check-ups and $80 \%$ were not engaged in exercise schedule. The study also revealed $66.3 \%$ of the subjects had not participated in their occupational related awareness programmes.

The present study revealed that overall percentage of health issues was around 19\% that shows the employees had one or the other type of health issue. Headache was the most frequent complaint (66.3\%) sounded by the subjects. Second common complaint was eye strain $(45 \%)$ followed by back pain $(43 \%)$. Less proportion $(28.8 \%)$ of the respondents were restless and $27.5 \%$ had gained weight.

There was a significant association between age $\left(\chi^{2}\right.$ $=16.20, \mathrm{p}<0.05)$, gender $\left(\chi^{2}=6.5, \mathrm{p}<0.05\right)$, religion $\left(\chi^{2}\right.$ $=33.80, \mathrm{p}<0.05)$, marital status $\left(\chi^{2}=49.37, \mathrm{p}<0.05\right)$, type of family $\left(\chi^{2}=45.0, \mathrm{p}<0.05\right)$, habits $\left(\chi^{2}=174.1, \mathrm{p}<0.05\right)$, frequency of habits $\left(\chi^{2}=48.05, p<0.05\right)$, years of job experience $\quad\left(\chi^{2} \quad=28.67, \mathrm{p}<0.05\right)$, type of shift $\left(\chi^{2}=45.0, p<0.05\right)$, average number of working hours $\left(\chi^{2}\right.$ $=72.20, p<0.05)$, rest period $\left(\chi^{2}=54.45, p<0.05\right)$, duration of rest period $\left(\chi^{2}=25.87, \mathrm{p}<0.05\right)$ and participation in health awareness program $\left(\chi^{2}=76.05, \mathrm{p}<0.05\right)$ with baseline characteristics. 
Table 1: Distribution of baseline characteristics in terms of frequency and percentage

$\mathbf{n}=\mathbf{8 0}$

\begin{tabular}{|c|c|c|c|}
\hline Sl. No & Baseline Characteristic & $\mathbf{f}$ & $\%$ \\
\hline \multirow[t]{3}{*}{1.} & Gender & & \\
\hline & Female & 48 & 60.0 \\
\hline & Male & 32 & 40.0 \\
\hline \multirow[t]{3}{*}{2.} & Religion & & \\
\hline & Hindu & 66 & 82.5 \\
\hline & Christian & 14 & 17.5 \\
\hline \multirow{4}{*}{3.} & Marital status & & \\
\hline & Married & 20 & 25.0 \\
\hline & Unmarried & 55 & 68.8 \\
\hline & Divorced / separated & 5 & 6.3 \\
\hline \multirow[t]{3}{*}{4.} & Type of family & & \\
\hline & Nuclear & 70 & 87.5 \\
\hline & Joint & 10 & 12.5 \\
\hline \multirow[t]{4}{*}{5.} & Monthly income (in Rs.) & & \\
\hline & $11,001-20,000$ & 17 & 21.3 \\
\hline & $20,001-30,000$ & 24 & 30.0 \\
\hline & 30,001 and above & 39 & 48.8 \\
\hline \multirow[t]{3}{*}{6.} & Frequency of personal habits & & \\
\hline & Not taken & 71 & 88.8 \\
\hline & Daily & 9 & 11.3 \\
\hline \multirow[t]{4}{*}{7.} & Years of job experience & & \\
\hline & Less than 1 year & 8 & 10.0 \\
\hline & 1 to 2 years & 25 & 31.3 \\
\hline & More than 2 years & 47 & 58.8 \\
\hline \multirow[t]{3}{*}{8.} & Annual health check-ups & & \\
\hline & Yes & 17 & 21.3 \\
\hline & No & 63 & 78.8 \\
\hline \multirow[t]{3}{*}{9.} & Engaged in exercise schedule & & \\
\hline & Yes & 16 & 20.0 \\
\hline & No & 64 & 80.0 \\
\hline \multirow[t]{3}{*}{10.} & Participate in health awareness programme & & \\
\hline & Yes & 1 & 33.8 \\
\hline & No & 79 & 66.3 \\
\hline
\end{tabular}

Table 2: Presence of Health Issues in terms of frequency and percentage

$\mathbf{n}=\mathbf{8 0}$

\begin{tabular}{|clcc|}
\hline \multicolumn{1}{c}{ Health Issue } & f & \% \\
\hline Sl. No & & 53 & 66.3 \\
\hline 1. & Headache & 22 & 27.5 \\
2. & Additional weight & 32 & 40.0 \\
3. & Drowsy & 36 & 45.0 \\
4. & Eye strains & 17 & 21.3 \\
5. & Redness / itching / dryness / blurring of vision & 0 & 0 \\
6. & Hearing Problem & 0 & 0 \\
7. & Ear pain & 0 & 0 \\
8. & Hoarseness of voice & 5 & 6.3 \\
9. & Shortness of breath & 7 & 8.8 \\
10. & Abdominal pain & 14 & 17.5 \\
11. & Indigestion problems & 14 & 17.5 \\
12. & Burning sensation of chest or abdomen & 6 & 7.5 \\
13. & Constipation & 8 & 10.0 \\
14. & Muscle strain / joint pain & 2 & 2.5 \\
15. & History of musculoskeletal injury & 11 & 13.8 \\
16. & Numbness in hands & 35 & 43.8 \\
17. & Back pain & 25 & 31.3 \\
18. & Neck pain & 9 & 11.3 \\
19. & Verbally aggressive during work & 1 & 1.3 \\
20. & Difficulty on focusing objects & 19 & 23.8 \\
21. & Feeling tired & 23 & 28.8 \\
22. & Restless & & \\
\hline & & & \\
\hline
\end{tabular}




\section{DISCUSSION}

The present study revealed that headache was the most frequent complaint (66.3\%) sounded by the subjects. Second common complaint was eye strain (45\%) followed by back pain (43\%). $28.8 \%$ of the respondents were restless and $27.5 \%$ had gained weight. The current study is supported by a study conducted in 2005 by Neevan R and Bobby Joseph where the results showed $78.40 \%$ of the subjects complained headache and $22.72 \%$ of the subjects had gained weight.11 There was a significant association between age, gender, religion, marital status, type of family, habits, frequency of habits, years of job experience, type of shift, average number of working hours, rest period, duration of rest period and participation in health awareness program with baseline characteristics The study conducted by Neevan R and Bobby Joseph in 2005 depicted that there is an association between marital status and health problems $\left(\chi^{2}=5.41, p=0.02, d f=1\right)$ as well as work

\section{REFERENCES}

1. Extending India's leadership of the global IT and BPO industries: NASSCOM-McKinsey report 2005. New Delhi: [cited on 2016 Dec. 20].

2. Vaid M. Health and population Innovation Fellowship Programme Working paper No. 10. New Delhi: population council; 2009. [cited on 2016 Dec. 20]. Exploring the lives of youth in BPO sector: Findings from a study in Gurgaon. Available from: http://www.popcouncil.org/pdfs/wp/India-HPIF/010.pdf.

3. Latha G, Panchanatham N. Call center employees: Is work life stress a challenge? Sabaramuwa Univ J. 2010; 9:1-9.

4. Ghazi S.N. "Occupational Stress in Call Centers": Myth or Reality, Abhigyan, v. 2006; 3(24):30-39

5. Sheena, J. "The Experience of Work Related Stress across a Occupations". Journal of Managerial Psychology, v.2005; 2(20):178-187

6. The daily Dinamalar : "Burn out stress syndrome” . 2004; 5 experience and musculoskeletal disorders $\left(\chi^{2}=8.04, \mathrm{P}<\right.$ $0.05, \mathrm{df}=3) \cdot{ }^{11}$

\section{CONCLUSION}

From the findings, it can be inferred that the longer the working hours, the more the health issues. The rest period ensures the less health issues. More the years of job experience more will be the health issues, the smokers had more health issues than the non smokers.

\section{Financial support and sponsorship:}

Nil

\section{Conflicts of interest:}

There are no conflicts of interest

Ethical Clearance: Taken from Ethics Committee of Yenepoya University

7. Suri JC, Sen MK, Singh P, Kumar R, Aggarwal P. Sleep patterns and their impact on lifestyle, anxiety and depression in BPO workers. Indian J Sleep Med. 2007; 2:64-70.

8. Kesavachandran C, Rastogi SK, Das M, Khan AM. Working conditions and health among employees at information technology - enabled services: a review of current evidence. Indian J Med Sci. $2006 ; 60: 300-7$

9. Gupta A. Health, social and psychological problems of women employees in BPO: A study in [India] 2012. [cited on 2013 January 3]. Available from: http://paa2012.princeton.edu/papers/121676.

10. Neelamegam R. "Work stress among employees" Journal of Management Research. 2010; 9: 57-69.

11. Naveen R, Bobby Joseph. Call Handlers and Their Health Problems. International Journal of Basic Medical Science. 2012; $3(3)$. 